\title{
Identidade e Liberdade: A conviç̧ão fundamental de Schelling
}

\author{
Identity and Freedom: \\ Schelling's fundamental conviction
}

\author{
Luiz Filipe da Silva Oliveira \\ Universidade Federal do Rio Grande do Sul (UFRGS) \\ Orcid 0000-0002-2790-8452 \\ luizfilipe3r@gmail.com
}

\begin{abstract}
Resumo: O objetivo deste trabalho é sustentar a ideia de que Schelling, apesar de ser considerado um pensador de diversas filosofias, manteve uma convicção fundamental no período que consiste entre seus primeiros escritos, de inspiração fichteana até a fase da filosofia da liberdade. Esta convicção era de que o incondicionado, Absoluto e/ou Deus no Eu e/ou Ser humano, deve ser pensado como tal, ou seja, independe da consciência. Observando sua performance a partir daqueles anos, isso permite balizar um padrão a partir do qual a fertilidade de seus intentos pode ser avaliada, ou seja, com base na aplicação dessa ideia. Este critério aparecerá no decorrer do texto na medida em que os argumentos de Schelling permitirem, contudo, elegemos como exemplo alguns escritos correspondentes às chamadas filosofias da identidade e da liberdade. Ao final deverá ser demonstrado que a transição de uma para outra correspondia a uma adequação filosófica necessária àquela convicção.
\end{abstract}

Palavras-chave: Schelling; Identidade; Liberdade; Deus; Absoluto; Ser humano. 
Abstract: The aim of this paper is to sustain the idea that Schelling, despite being considered a thinker of various philosophies, maintained a fundamental conviction in the period that consists among his first writings, of Fichtean inspiration until the phase of the philosophy of freedom. That is, that the unconditioned, Absolute and/or God in the I and/or Human being, must be thought as such, that is, independent of conscience. Observing his performances from those years on, this allows us to set a pattern from which the fertility of their attempts can be assessed, that is, based on the application of this idea. This criterion will appear in the course of the text to the extent that Schelling's arguments allow, however, we have chosen as an example some writings corresponding to the so-called philosophies of identity and freedom. In the end it should be demonstrated that the transition from one to the other correspond to a necessary philosophical adequacy to that conviction.

Keywords: Schelling; Identity; Freedom; God; Absolute; Human being.

Manfred Frank inicia sua obra Reduplikative Identität. Der Schlüssel zu Schellings reifer Philosophie relembrando um dito de Dieter Henrich sobre os três expoentes do Idealismo Alemão:

Fichte, Schelling e Hegel compartilharam a convicção fundamental de que seria pensado no Eu autoconsciente um incondicionado. Fichte colocou o acento no Eu como o lugar deste pensamento, Hegel na pretensão de captar o incondicionado no Eu através do pensamento. Schelling, no entanto, tinha dado à sentença esta reviravolta: ' $O$ incondicionado no Eu deve ser pensado como tal' (FRANK, 2018, p. 1).

Esta reviravolta antecipa, em certo sentido, o empreendimento realizado por Schelling no que diz respeito à conviç̧ão fundamental que ele sustentava já em seus primeiros escritos. Diante desta convicção, no Vom Ich e nas Cartas sobre o dogmatismo e o criticismo (ambos datados de 1795), Schelling permite entrever o árduo caminho a ser percorrido por sua filosofia. $\mathrm{O}$ objetivo não é outro senão a conciliação entre o criticismo e o dogmatismo; ou, para dizer em termos fichteanos, entre o Eu e o não-Eu, uma vez que, conforme ele por vezes assinala, o criticismo pode ser visto como o exagero do Eu em detrimento do não-Eu e o dogmatismo como o exagero do não-Eu sobre o 
Eu. Isso fica mais claro na carta que Schelling escreve a Hegel em 04 de fevereiro de $1795 .^{1}$

Não obstante, isso conecta-se à referida citação de Frank suscitando Henrich de modo que, na visão schellinguiana e diferente da tradição do criticismo em voga, "o incondicionado [...] independe da consciência" (SCHELLING, SW I/1, p. 100; apud FRANK, 2018, p. 1). Por conseguinte, é possível dizer que Schelling discordara mais da letra kantiana do que Fichte, uma vez que não estava disposto a se manter naquela posição ainda conservadora de assegurar confiança na autonomia prática do ser humano enquanto se mantinha altivo nos limites teóricos do Eu autoconsciente, subordinado à relação sujeito-objeto. ${ }^{2}$ Em outras palavras, para o jovem Schelling, o Eu absoluto "não é reconhecível a partir da posição da pessoa explicitamente consciente de si mesma" (FRANK, 2018, p. 2). Em suma, conforme Schelling destaca nas Cartas, "nenhuma proposição pode ser, segundo sua natureza, mais infundada do que aquela que afirma um Absoluto no saber humano" (SCHELLING, 1989, p. 18). Isto pode ser apresentado como a tentativa schellinguiana de se livrar dos rastros do espírito epistemológico no qual o criticismo foi limitado, principalmente pela versão difundida por Reinhold. Essa foi também a conviçção fundamental que Schelling assumiu e balizou sua filosofia, seja ela a da natureza, da identidade, da liberdade, etc. Dizemos isso tão somente na medida que seus intentos não lineares admitem uma avaliação baseada

\footnotetext{
1 "A verdadeira diferença entre filosofia crítica e dogmática parece-me residir no fato da primeira partir do Eu absoluto (ainda não condicionado por nenhum objecto), esta última parte do objeto absoluto ou do não-Eu. A última, na sua máxima consequência leva ao sistema de Espinosa, a primeira, ao sistema de Kant. A filosofia deve partir do incondicionado" (SCHELLING, apud HEGEL, 1952, p. 22).

2 Segundo Dreher, a relação entre dependência e liberdade em Schelling e Schleiermacher aponta que ambos os autores "diferem, no geral, da concepção exposta na filosofia prática de Kant e no idealismo subjetivo do jovem Fichte. Pois este último, Fichte, no intuito de suplantar a 'falta de princípio unitário' no pensamento de Kant e também a Elementarphilosophie de Karl L. Reinhold - que postulava a dependência do sujeito em relação aos objetos no âmbito teórico e sua independência, autonomia ou liberdade no âmbito prático -, pensara ter descoberto o princípio mais puro da filosofia na absoluta liberdade do eu (o Ich)" (DREHER, 2004, pp. 61-62).
} 
na fertilidade de sua aplicação. Mostraremos isso a seguir na passagem da filosofia da identidade para a da liberdade.

Foi com base nessa convicção fundamental que a inclusão de elementos da filosofia de Espinosa, reiteradamente apropriados na época, pareceu oportuna no contexto da discussão sobre os destinos da filosofia transcendental. Contudo, essa relação não foi construída de modo antagônico. É devido lembrar que Schelling estava imerso no ambiente proporcionado pela difusão da filosofia crítica, além de que o resgate de Espinosa em tal contexto ocorreu inclusive pela natureza da filosofia transcendental fichteana:

Ele [Espinosa] acreditava concluir fundado em argumentos teóricos, onde era impelido meramente por uma carência prática; que ele acreditava estabelecer algo efetivamente dado ao estabelecer meramente um ideal proposto, mas nunca alcançável. Reencontraremos sua unidade suprema na doutrina-da-ciência; mas não como algo que é, e sim como algo que por nós deve ser produzido, mas não pode sê-lo. Assinalo ainda que se se transgride o eu sou chega-se necessariamente ao espinosismo [...] e que só há dois sistemas plenamente consequentes: o crítico, que reconhece esse limite, e o espinosista que lhe salta por cima (FICHTE, 1984, p. 49).

Em poucas palavras, Fichte afirma que a consequência fundamental da filosofia de Espinosa está balizada à luz de uma exigência prática da razão; apesar dele (Espinosa) tentar fundamentar isso em vias teóricas. Assim, era pressuposto que, por conta dessa demanda prática, o espinosista saltava por cima dos limites estabelecidos pela crítica transcendental, apoiando-se seguramente naquilo que "deve ser".

Essa discussão - que remete duplamente a Jacobi, principalmente por causa de sua importância nas querelas do panteísmo e do ateísmo - pareceu profícua aos olhos de Schelling, dado que o próprio Fichte apresentava seu sistema não como antípoda do dogmatismo, mas simplesmente como um concorrente direcionado ao mesmo objetivo. No entanto, a transição de toda essa problemática ao âmbito prático não cancelava aquela convicção que a filosofia de Schelling havia alcançado. Melhor dizendo, ele não estava disposto a reduzir esta questão a uma discussão teorética sobre as condições de 
possibilidade do agir moral. Devido a essa convicção, calcada no saber da insuficiência de respostas da razão especulativa acerca da fundamentação da ação, foi levado a conceber "um conceito que não só explicasse as condições de possibilidade do agir humano em geral, mas que sondasse, igualmente, a finalidade ética mais ampla, que inclui a significação metafísica de tal agir" (DREHER, 2004, pp. 60-61). Neste sentido, a introdução de Espinosa servia exatamente para consolidar aquela transição da questão ao âmbito prático, conforme havia sido iniciado com Fichte, mas também para escapar daquela dualidade entre ser e pensar, peculiar à filosofia transcendental.

Ao seguir este caminho, a carência de um "fundamento mais profundo do que a simples faculdade-de-conhecer" (SCHELLING, 1989, p. 9), necessitada de uma significação metafísica do agir, somente se satisfaria mantendo-se no espírito prático da Doutrina da Ciência. No entanto, "o admirador de Fichte logo sairia de sob suas asas em busca do calor e da luz de sua visão original de um mundo e uma natureza preenchidos por Deus" (COELHO, 2018, p. 15). Vai ser exatamente por isso que a relação entre o indivíduo e o Absoluto, entre o homem e Deus, não pode ser vista do mesmo modo como a relação entre sujeito e objeto, consciência e natureza. Pelo contrário, a partir da influência de Jacobi, conforme Christian Iber sustenta, Schelling sabia que "a filosofia deve partir do incondicionado" (IBER, 2015, p. 25). Não obstante, na esteira da tradição do iluminismo alemão, ele não estava disposto a abrir mão de princípios fundamentais da liberdade humana, tal qual Kant ensinara. Isso significava pôr em voga a perspectiva de uma metafísica da totalidade que ao mesmo tempo em que caminhava a partir de um princípio prático, não apenas teórico, fazendo-se valer então daquela convicção fundamental, pretendia resguardar o espaço para autonomia do agir humano. Talvez seja essa a fase do pensamento de Schelling onde é mais visível o acirramento entre o panteísmo de inspiração romântica e o ideal iluminista de uma metafísica da liberdade (humana) preocupação tão cara, por exemplo, à teologia protestante de seu tempo. Essa mediação representava certamente a irrupção do problema da conciliação entre dependência e liberdade. 
Se com Fichte tínhamos o desenvolvimento de uma retomada da capacidade de representação dos sujeitos a partir da consciência voltada a si mesma, com Schelling, apresenta-se uma nova consideração acerca do impulsionamento vital desta capacidade. Assim, já em suas Idéias para uma Filosofia da $\mathrm{Na}$ tureza (1797), passa a considerar tanto o elemento subjetivo quanto o objetivo como atividades originárias. Isto significava uma ampliação dos princípios fundamentais ao tipo de filosofia que se elaborava até então. Estes princípios não seriam balizados mediante as condições do conhecimento, ou seja, a partir das disposições da subjetividade, mas estaria para além da relação sujeito-objeto. Schelling pretendeu assim colocar-se para além da divisão entre dogmatismo e criticismo, unificando em seu princípio absoluto a justaposição tanto do espinosismo (necessidade), quanto do criticismo (liberdade).

De acordo com o apontamento de Luís Dreher, "o par conceitual 'liberdade e dependência' não configura, para Schelling [...], uma alternativa, um 'ou-ou'; configura, isto sim, um 'tanto-como', um 'e também' de liberdade e dependência” (DREHER, 2004, p. 61). Frente a isso, podemos entender que este amálgama de dois termos aparentemente excludentes pressupõe uma realidade onde o agir humano deixa-se entrever apenas em meio a uma condição metafísica por excelência. Aqui há o caráter de necessidade porque pressupõe plena interposição de um e outro, de forma que nenhum dos lados seja sobrepujante. Por conseguinte, é dado cabo àquela convicção fundamental já mencionada, ou seja, de que a verdade não pode ser vista a partir da posição do sujeito consciente. Essa convicção é mantida por Schelling durante o resto de sua produção. A consequência imediata disso será a necessidade pungente da realidade metafísica daquilo que é o caso do mundo, onde a verdade do sujeito em relação com a natureza, onde ele se encontra incluído, não poder ser dada epistemologicamente.

A questão é que a fundamentação dessa realidade sobre aquilo que é o caso do mundo não poderia ser feita a partir das bases teóricas, a saber, que partem da relação entre natureza e consciência. Mesmo no Sistema do idealismo transcendental (1800), o filósofo seria incapaz de representar o incondiciona- 
do. O acesso exclusivo era dado ao gênio artístico, único capaz de romper as restrições impostas pela consciência e, a partir da intuição intelectual, representar a identidade pela espontaneidade de sua atividade criativa. ${ }^{3}$

A filosofia da identidade inaugurada posteriormente com a pompa de ser o verdadeiro sistema de filosofia de Schelling, representou o distanciamento público deste para com Fichte: "a operação fundamental do novo sistema de identidade consiste assim na 'dessubjetivação' da identidade do real e do ideal, que por si só pode reivindicar o título de ser: focalização naquilo que é" (FRANK, 2018, p. 100). Schelling, como expoente idealista, ao invocar "aquilo que é", assume um sentido completamente diferente do que pressupunha a versão do idealismo em sua vertente subjetivista. Em carta de 1805 a Eschenmayer, ele declara que a Darstellung de 1801 era produto de uma epifania, "quando a luz irrompe sobre mim na filosofia" (SCHELLING, 1962, p. 222).

Diferente da imagem que Schelling poderia estar querendo construir sobre sua própria trajetória, Frank (2018, p. 99) concebe a Darstellung como um caso estrategicamente pensado ao salientar que o autor sentiu a necessidade de apresentar definitivamente seu próprio sistema de filosofia, uma vez que havia sido tratado em relação a Fichte apenas como um "colaborador espiritual" da então versão que este trabalhava da Doutrina da Ciência. Através da publicação de Darstellung meines Systems der Philosophie - cuja ênfase dada ao pronome possessivo foi motivo de chacota entre seus coetâneos; mas que no mínimo é certamente curiosa mediante uma proposta que rejeitava perspectivas subjetivas - Schelling encontrou a oportunidade de provar-se enquanto pensador de espírito próprio, uma vez que seus tratados precedentes, da filosofia da natureza do idealismo transcendental, apesar de tudo, ainda haviam sido assimilados como simples aperfeiçoamentos da filosofia transcendental sob o aspecto fichteano. ${ }^{4}$

\footnotetext{
$3 \quad$ Cf. Schelling, 2005, p. 416.

4 Exemplo claro disso foi todo o mal-entendido prévio com Eschenmayer que solicitara de Schelling um melhor tratamento para a filosofia transcendental antes de apresentar sua filosofia da natureza.
} 
Foi a partir dessa necessidade filosófica e pessoal, que brotaram propostas paradoxais à perspectiva subjetivista, tal como sua concepção da intuição intelectual que, ao mesmo tempo que correspondia a um ato que ocorria em relação ao sujeito, em sua relação mais apropriada com a realidade do todo, possuía um fundamento não subjetivo. A respeito disso, Schelling, em seu Über den wahren Begriff der Naturphilosophie de 1801, dizia: "reivindico a intuição intelectual conforme reivindicada pela Doutrina da Ciência; mas também exijo a abstração do intuinte nesta intuição" (SCHELLING, 1996, p. 263).

Considerando os desenvolvimentos de Schelling a partir de 1801, na então conhecida filosofia da identidade, onde "tudo o que é é a própria identidade absoluta" (SCHELLING, 2001, p. 352), a perspectiva onde liberdade e necessidade não são concebidas como pares opostos parecia obter validade sistemática. No entanto, tal como Schelling mesmo afirma em diversas passagens, o ponto de vista da identidade deve ser semelhante a completa indiferença e as perspectivas opostas como referidas precisamente ao saber provindo do entendimento. O fato paradoxal a partir de então era que se a liberdade fosse entendida em oposição à necessidade, a identidade absoluta perderia sua substância una e, então, se dissolveria; mas, ao contrário, estabelecer a completa identidade entre tais era equivalente a conceber a indiferença entre eles, isto é, seu valor determinante desaparecia inteiramente diante daquela substância absoluta. Neste sentido, Schelling mesmo afirma em sua Filosofia da Arte (1802) que "o Absoluto não é em si nem consciente, nem inconsciente, nem livre, nem não-livre ou necessário" (SCHELLING, 2010, p. 41). Ele aqui se deparou com o problema do antídoto aplicado contra a possibilidade de visões parciais na filosofia, diga-se subjetivistas, ao molde fichteano, ou seja, aquela sua convicção fundamental de que o incondicionado independe da consciência, retirar toda e qualquer possibilidade de ação livre, mesmo na determinação, uma vez que algum nível de consciência é pressuposto para a autonomia.

Naquele momento, Schelling presume que todo nível de liberdade é baseado na oposição entre possibilidade e efetividade. Melhor dizendo, toda ação por liberdade pressupõe diferen- 
tes possibilidades onde uma, unilateral, seria então realizada. Desta forma, se todas as coisas coincidem e subjazem no Absoluto, não há possibilidade de liberdade. Da mesma maneira, se ele é aquilo que é o caso, tampouco se poderia dizer que é necessário, uma vez que necessidade remonta ao cumprimento de algo alheio, de alguma vontade ou propósito. Se ambos os conceitos, liberdade e necessidade, eram diferentes, como poderia Schelling provar que eram idênticos; e, se eram idênticos, como ele poderia provar que eram diferentes? Doravante, estava aberto então um flanco para as mais diversas críticas que receberia a filosofia de Schelling. Os exemplos mais claros são as de Hegel, primeiramente de modo velado ${ }^{5}$, e as que viriam posteriormente de maneira pública, como as de Eschenmayer, entre outras.

Se, conforme a leitura de Iber (2015, p. 25) trazida acima, havia sido de Jacobi que Schelling retirou a lição fundamental de que se deve partir diretamente do incondicionado, o modo como essa premissa havia sido correspondida na filosofia da identidade, planejada ao mos geometricus de Espinosa e com símiles consequências teológicas, tampouco satisfaria aquele que, por motivos parecidos, tivera sido figura presente nas querelas do panteísmo, com Lessing, e do ateísmo, com Fichte. ${ }^{6}$ Através da Darstellung, Schelling adentrava num terreno que Jacobi historicamente havia tornado árido, e cujas consequências parecia anunciar uma espécie de dèja-vu que só pôde ser mitigado, a princípio, graças ao fracasso das pretensões anunciadas pelo título do tratado, ou seja, tampouco aquele constructo foi tomado como o sistema definitivo da filosofia de Schelling.

Percebemos esse fracasso através do fato de Schelling publicar, num curto período, sucessivos novos tratados estabelecendo sucessivas novas expressões para o princípio de que partia: ele foi ontologicamente chamado de Deus ou o Absoluto e epistemologicamente considerado a indiferença do subjetivo e do objetivo, na própria Darstellung, de identidade da identidade, e a identidade da identidade e da diferença nas Ferneren Darstellungen aus dem System der Philosophie de 1802 e

5 Segundo Tilliette (1968, p. 163), o Escrito da Diferença de Hegel, também de 1801, demarca as diferenças entre Schelling e Hegel.

6 Cf. Beckenkamp, 2004, pp. 19-20. 
no diálogo Bruno de 1802/03, a identidade da afirmação e do afirmado no Würzburger System de 1804, e cópula ou vínculo na Abhandlung Über das Verhältnis des Realen und Idealen in der Natur de 1806 (VATER, 2014, p. 129).

A natureza ambígua dos trabalhos concentrados nesse período levou, por exemplo, Jean-François Marquet a descrevê-los como "muito semelhantes para exigir estudos separados, e muito diferentes para derivar alguma fórmula em comum deles como sistema" (1973, p. 208). De certa maneira, essa perspectiva não censura a combinação da afirmação de Jochem Hennigfeld de que no escrito Philosophie und Religion (1804) "o princípio da filosofia [tal qual inaugurado na Darstellung] é e continua sendo o Absoluto enquanto a identidade imediata do ideal e do real, iluminado por intuição intelectual" (HENNIGFELD, 2011, p. 20), ou seja, de que corresponde a uma continuidade para com seus escritos anteriores, com a de Dreher, para quem, naquele escrito, a introdução do conceito de "salto" (Sprung) "explica a passagem para o mundo real [...] que emerge apenas por um afastamento a partir da liberdade" (DREHER, 2004, p. 71). Pelo contrário, elas podem ser consideradas complementares, uma vez que este elemento, que tornará possível a intromissão da pauta desse ato de liberdade, pressupunha paradoxalmente, como sempre foi o caso, a afirmação filosófica da identidade formulada sob a base do monismo de sistema. $\mathrm{O}$ primeiro passo para a compreensão desse aparente paradoxo é observar que Schelling começou, a partir de então, a delinear a posição de que "enquanto identidade do subjetivo e do objetivo, o Absoluto é, ao mesmo tempo, um autoconhecimento, uma autorrepresentação" (HENNIGFELD, 2011, p. 20). Grosso modo, pautava-se pela primeira vez, desde então, uma possibilidade de diferenciação no Absoluto:

Quanto a essa diferença em si, porém, ela só poderia existir na medida em que a mesma identidade se tornasse objetiva em formas particulares; mas essas formas, uma vez que se tornam nelas o geral, a Absolutidade, se torna uma com o particular, de tal forma que nem aquela é suprimida por este nem este por aquela, só poderiam ser ideias. Mas nas ideias estão as meras possibilidades das diferenças e não a diferença real, pois cada ideia é um universo para si, e todas as ideias são como uma só ideia. Portanto, se aquele diferenciar-se 
do Absoluto fosse compreendido como autoconhecimento, como um diferenciar-se real, ela não ocorreria nem mesmo na imagem do Absoluto, menos ainda, portanto, em si mesmo; pois, se ele se diferencia, não se diferencia em si mesmo, mas em outro, que é o seu real, e este também não se diferencia de si por si, mas pela forma que flui da plenitude da sua absolutidade como elemento independente, sem seu agir (SCHELLING, 1804, pp. 27-28).

De certa maneira, é possível notar aqui uma continuidade com seus escritos anteriores. Utilizando a linguagem da Darstellung, Schelling está afirmando que essa diferenciação não ocorre qualitativamente. Sob a perspectiva de Philosophie und Religion essa diferenciação enquanto autoconhecimento pode ser organizada da seguinte maneira: (1) há o Absoluto real em si mesmo; (2) há as ideias, em uniformidade com Absoluto, mas em outra forma, como uma imagem; (3) há o autoconhecimento do Absoluto a partir da sua imagem enquanto unidade imediata do ideal e do real, mas que não deve ser entendido como uma característica incidental, uma vez que "a unidade e a multiplicidade no Absoluto são mostradas e preservadas; mas o mundo finito não é obtido por ele" (HENNIGFELD, 2011, p. 20).

Ademais, a relação entre o Absoluto e a diferença, entre real e ideia, não pode ser entendida à luz do princípio de causa e efeito, pois a possibilidade da concepção de causa e causado ocasionaria um contraste incompatível com a realidade do Absoluto enquanto identidade. O que estava por trás desta afirmação é a noção schellinguiana que concebia não haver passagem do infinito ao finito. Aquele autoconhecimento é absoluto como um momento do próprio Absoluto. O motivo seria a constatação de que "inúmeras tentativas de produzir uma continuidade entre o princípio supremo do mundo intelectual [logo, do Absoluto] e da natureza finita foram feitas em vão" (SCHELLING, 1804, p. 30). Por isso, "o Absoluto é o unicamente real, por outro lado, as coisas finitas, não são reais" (SCHELLING, 1804, p. 35).

A tônica de Schelling em princípios caros para sua filosofia da identidade foi realizada por conta de Philosophie und Religion ter ocorrido, entre outras coisas, por ocasião de Die Philosophie in ihrer Uebergang zur Nichtphilosophie (1803) pu- 
blicado por Eschenmayer. Schelling vem a público denunciar a supressão da filosofia que aquele proclamava, buscando "mais uma vez complementar a filosofia com a fé" (SCHELLING, 1804, p. 3). Não por menos, o próprio tratado de Eschenmayer surgira como um contraponto à exclusão inconsciente da filosofia da identidade do problema da liberdade. A necessidade de uma não-filosofia, segundo Eschenmayer, dava-se como consequência da consideração de aquilo que, enquanto objeto, "é ele mesmo retirado [entrückt] da especulação e, em geral designa os limites do conhecimento" (ESCHENMAYER, 1803, s/n), não sendo, portanto, objeto da filosofia, mas da teologia.

Eschenmayer parecia estar de acordo com a convicção fundamental de Schelling de que o Absoluto seria inacessível pela posição do Eu consciente, isto é, com o elemento de epistemologia negativa da filosofia da identidade. Mas não apenas isso, Eschenmayer admitiu também que a especulação schellinguiana seria o ponto mais alto entre as possibilidades da filosofia. Contudo, quanto ao programa positivo, ou seja, especulativo, alega que não consiguia dar conta do problema específico da origem da diferença no contexto da identidade absoluta, assim, ao problema da liberdade. ${ }^{7} \mathrm{O}$ paradoxo era que a filosofia, em seu ponto mais elevado, levaria naturalmente à religião.

Segundo Eschenmayer, o amorfismo da indiferença, figurada enquanto substância absoluta, única forma que a filosofia poderia conceber o Absoluto, uma vez que este é o resultado da filosofia de Schelling, - ponto alto das possibilidades filosóficas - fosse transfigurada numa espécie de voluntarismo teológico de inspiração cristã: "Esta indiferença é a vontade absoluta. A vontade é o ponto de passagem do mundo invisível da fé para o mundo visível do conhecimento; é precisamente a partir deste ponto que a espontaneidade é o fator incondicionado de toda especulação" (ESCHENMAYER, 1803, p. 47). ${ }^{8}$ É

$7 \quad$ Para uma consideração completa das críticas de Eschenmayer, Cf. Florig, 2008, pp. 81-87.

8 "De acordo com Eschenmayer, o Absoluto só é produzido pela transição para a fé. Na medida em que o Absoluto é o ponto de transição do conhecimento para a fé, é ao mesmo tempo evidente que o Absoluto traz em si a semente da diferença. Como ponto de transição, o Absoluto é também o mediador da liberdade" (FLORIG, 2008, p. 84). 
a prevalência de tal voluntarismo que tanto Coelho (2018, p. 21) quanto Dreher (2017, pp. 46-47) afirmam que Schelling, embebido por elementos da teologia e da mística cristãs, principalmente de Lutero e Böhme, defenderá posteriormente nos escritos pertencentes à fase da filosofia da liberdade, como sombra que cobrirá toda a sua filosofia.

Embora Eschenmayer declare a filosofia da identidade como o ponto alto da filosofia, percebe que certos elementos fundamentais, como a liberdade, não admitem nenhuma sondagem pela natureza da própria filosofia, ainda que ele acreditasse ser a filosofia de Schelling aquela que alcançou o ponto máximo da razão. Em suma, Eschenmayer, abandonou a filosofia transcendental, se entregou à engenhosidade sistemática da filosofia da identidade, pois considerava essa a única possível, e não muito depois se viu na encruzilhada de ter de apostar na não-filosofia para não contraditar de vez a perspectiva de Schelling.

A não-filosofia lançada por Eschenmayer - cuja consequência não é outra senão a revalorização da fé, próxima à concepção de Jacobi - deve ser vista enquanto fruto imediato da acusação de imobilidade derivada da filosofia da identidade. Essa imobilidade pode-se ser concebida como resultado do aprofundamento daquela convicção fundamental de Schelling, de que o incondicionado independe da consciência. Essa imobilidade leva Eschenmayer a afirmar que "o que a especulação nunca pode fazer, a fé ainda pode fazer; só ela ainda designa aquela linha além do conhecimento [...] sem jamais alcançá-la" (ESCHENMAYER, 1803, pp. 31-32). O fato é que após a aposta no monismo de sistema, concebido para fazer jus à lição derivada de Jacobi, a saber, que é preciso partir diretamente do incondicionado, a lição velada de Eschenmayer foi que seria melhor voltar à fé daquele que partia do mistério insondável da liberdade e que, recorrendo a um salto mortale, ousou não fundar sua filosofia, mas antes expor aos olhos do mundo sua obstinação não-filosófica, mesmo de modo temerário (JACOBI, 2004, p. 214). De outra maneira, Eschenmayer se referia ao fato de que o que escaparia a Schelling era exatamente a lição de que aquela convicção fundamental não poderia ser realiza- 
da pela filosofia, que sempre resguardaria aspectos da separação entre sujeito e objeto.

Há quem acredite, como Sebastian Gardner (2016, p. 329), que a ideia de Schelling quanto a inadequação da razão teórica em produzir conhecimentos verdadeiros é retirada de Jacobi. No entanto, no que diz respeito ao desdobramento da derivação deste princípio, houve desde o início da produção schellinguiana uma profunda diferença. O fideísmo de Jacobi obrigava-o a pronunciar a incapacidade da filosofia de revelar um fundamento seguro, permanecendo fixo à rigidez do conhecimento enquanto derivação da Glaube, algo próximo ao que Eschenmayer buscava retroceder. Schelling, por outro lado, parte da tentativa de uma revolução interna ao próprio desenvolvimento do método filosófico. Para ele, a filosofia deveria, em sua raiz, desenvolver suas formas de acesso a Deus e/ou Absoluto a partir de um tipo não-comum, e puramente inovador. $\mathrm{O}$ ápice foi alcançado através do método da intuição intelectual do sistema da identidade. As críticas de Eschenmayer, desferidas previamente, no entanto, colocaram a questão se o arsenal filosófico da filosofia da identidade seria capaz de captar o Absoluto em sua face insondável. Em outras palavras, se permitia Schelling levar sua convicção fundamental às últimas consequências.

A resposta de Schelling, desenvolvida em Philosophie und Religion, parte exatamente daquele ponto da imanência das coisas no Absoluto. Para ele, as críticas tais quais a de Eschenmayer pressupõem o Absoluto enquanto um mero resultado, como se só coubesse à filosofia ser uma atividade sintetizadora que produziria apenas um amontoado de caracterizações a partir das quais o filósofo pensaria a ideia do Absoluto. Em poucas palavras, como uma unidade de princípios antagônicos, tais como liberdade e necessidade. Neste caso, tais ideias são as mais elevadas, cabendo ao Absoluto dar a possibilidade da coexistência desses princípios que ao entendimento são opostos. Para Schelling, críticos como Eschenmayer não percebem que o próprio filósofo exige algo bem diferente para o conhecimento do Absoluto e que a intuição intelectual "constitui o em si mesmo da alma, e que se chama intuição somente porque a essência da alma é ela mesma una com o Absoluto e não pode ter 
outra coisa senão relação direta com ele" (SCHELLING, 1804, p. 11). Com isso, Schelling quer dizer que o Absoluto deve ser pensado enquanto tal. Assim, aqueles que "aderem apenas a essas descrições negativas não podem ver a verdadeira essência do Absoluto como divina. [...] não conseguem realmente superar os opostos" (HENNIGFELD, 2001, p. 24). Segundo Schelling, é daqui que decorre a fonte da separação entre Absoluto e Deus, feita por Eschenmayer, e, assim, daquela entre filosofia e religião.

Primeiramente, esta afirmação deve então ser contraposta diretamente àquela de que o autoconhecer-se independentemente do puramente ideal é uma eterna transformação da pura idealidade em realidade; ou seja, embora toda representação finita pudesse ser apenas ideal, o autoconhecimento do Absoluto deveria ser ao mesmo tempo, real. Isto enquanto momento ulterior de um ato de autodiferenciação do próprio Absoluto. Ato producente de uma imagem que é, em si mesma, absoluta. Diferente daquele ajuntamento de ideias que Schelling acusa Eschenmayer de fazer, a saber, partir de ideias para se alcançar o Absoluto - o que só poderia resultar num Absoluto puramente negativo - no autoconhecimento da divindade, as ideias são estabelecidas como formas reais do Absoluto em seu processo de diferenciação, ou seja, a elas era pressuposta a unidade com o real. Cumpriam, por sua vez, sua razão na "auto-objetivação do Absoluto" (SCHELLING, 1804, p. 37), ou seja, uma diferença entre idealidade e realidade em um real que se diferencia em si mesmo.

Contra Eschenmayer, Schelling diria que o "que ele quer manter pela fé é a mesma absolutidade que nós possuímos num claro saber e igualmente numa clara consciência deste saber" (SCHELLING, 1804, p. 55). Diferente daquela "absolutidade" interpretada por Eschenmayer, assim como por outros detratores da filosofia da identidade, Schelling chama atenção, agora numa escrita claramente mais apropriada, ao fato de que "o que é exclusivamente peculiar na absolutidade é que ela também dá à sua imagem, a essência [Wesen] de si mesmo, independência" (SCHELLING, 1804, p. 36). 
De acordo com Walter Ehrhardt, este ponto de essência referido aqui, alcançado ainda sob a perspectiva da intuição intelectual, não pode ser confundido com aquele ponto de abstração do intuinte na intuição que Schelling mesmo exigia outrora, que gerou discussões com Fichte e esteve no centro da disputa de 1801 a respeito do conceito de espontaneidade de Eschenmayer. Ehrhardt diz que "Schelling usa apenas o sentido quase perdido de vivacidade [Lebendigkeit] para o verbo Wesen" (EHRHARDT, 2008, p. 65). Portanto, faz referência a um ser daquele a quem "nenhuma essência [Wesen] pode ser atribuída a não ser pelo seu conceito" (SCHELLING, 1804, p. 21). A partir dessa vivacidade, designada pelo verbo Wesen à imagem, ou seja, às ideias, podemos falar assim de uma "vida dupla' das ideias" (HENNIGFELD, 2001, 27). Dupla no sentido de que são elas mesmas absolutas enquanto produtivas, semelhantes à imagem a qual o Absoluto se conhece enquanto real, embora independente delas:

Esta é a verdadeira teogonia transcendental: não há nesta região outra relação que não a absoluta, que o velho mundo, na sua forma sensível, só soube expressar através da imagem da geração, em que o gerado é dependente do gerador e nem por isso deixa de ser independente (SCHELLING, 1804, p. 30).

O que Schelling pretendia demonstrar com isso era ter alcançado a possibilidade de garantir um universo gerado sem que padecesse de restrições da finitude pela única e mera razão de ter sido gerado, um universo de coisas absolutas, onde "não há nada que não seja absoluto, ideal, alma inteira, pura natura naturans" (SCHELLING, 1804, p. 30). E quanto à produção da natura naturata? Ora, afinal foi a insuficiência da filosofia da identidade frente a essa questão que levou Eschenmayer apostar num ato de vontade da indiferença, diga-se de Deus, constatável apenas através da fé.

Schelling estava convencido quanto a impossibilidade de qualquer teoria emanacionista ou dualista. Enquanto a primeira conduziria ao erro de introduzir uma contradição absoluta, pois pressupõe a transição do Absoluto para o seu oposto, estabelecendo um antagonismo entre o Absoluto e o não-Absoluto, o infinito e o finito; a segunda negaria o conceito do 
Absoluto por definição. No mais, ambas estabelecem inevitavelmente, o dilema da teodiceia, a saber, de apresentar Deus enquanto autor do mal (SCHELLING, 1804, p. 34).

A resposta de Schelling depende, grosso modo, do sucesso de sua explicação da autonomia que ele deposita nas ideias como imagem do Absoluto. Levando a termo, sendo a imagem absoluta, portanto livre, a ela é permitida uma separação do Absoluto em via de realização de sua autonomia, correspondendo àquilo que apresentamos como "vida dupla das ideias". Tal qual o Absoluto real criou uma imagem de si, a ideia enquanto liberdade quer se realizar como sendo independente do Absoluto. Enquanto nesse, reinava a identidade absoluta de liberdade e necessidade, ambos, enquanto imagem, se separam através de uma queda [Abfall], cujo fundamento residia na liberdade, que por sua vez fundamenta toda a realidade (SCHELLING, 1804, p. 38). ${ }^{9}$

Em suma, não há passagem contínua do Absoluto para o real. A origem do mundo dos sentidos só é concebível como uma ruptura completa com a Absolutidade, através de um salto. Se a filosofia pudesse derivar a origem das coisas reais de modo positivo desde o Absoluto, então seu fundamento positivo precisaria residir no Absoluto, mas em Deus apenas o fundamento das ideias é mantido, e também as ideias produzem imediatamente novamente ideias, e nenhuma atuação positiva emanada delas ou do Absoluto faz uma ligação ou ponte do Infinito para o finito. Além disso, a filosofia tem uma relação meramente negativa com as coisas aparecentes, ela não demonstra nem que elas são nem que elas não são: então como pode dar-lhes alguma relação positiva com Deus? O Absoluto é o único real, enquanto as coisas finitas não são reais; seu fundamento não pode estar numa comunicação da realidade para elas ou para seu substrato, comunicação esta que tivesse saído do Absoluto; ele somente pode residir num distanciamento, numa queda do Absoluto (SCHELLING, 1804, pp. 34-35).

Aquela imagem, como autoconhecimento de Deus, ou seja, enquanto universo ideal, participa da unidade. Contudo, através do uso da liberdade que lhe foi conferida, enquanto protótipo [Urbild], quer estar em independência em relação ao próprio Absoluto. Este é assim o seu enredar-se [verwickelt] num $9 \quad$ Segundo Dreher, "característico das ideias é compartilharem da liberdade, o ser-em-si-mesmo de Deus. A possibilidade de tal desprendimento está assim dada pela autonomia intrínseca das ideias que são o reflexo ou imagem (Gegenbild) do Absoluto" (DREHER, 2004, p. 71). 
ato de necessidade (SCHELLING, 1804, p. 37). Para Hennigfeld, esta tese, que rejeita todas as tentativas de derivação e mediação, contém uma visão positiva: "o salto (ou queda) é um começo repentino, é a espontaneidade, ou seja, a capacidade de iniciar uma série de fenômenos por si só. [...] a queda deve ser um ato de liberdade" (HENNIGFELD, 2011, pp. 20-21, grifo nosso).

É curioso como a atribuição da queda enquanto espontaneidade, ou seja, por liberdade, remete a outra disputa entre Eschenmayer e Schelling no tocante à predominância da filosofia da natureza ou da filosofia transcendental. Esta disputa ocorreu anos antes, em 1801, com as publicações de Spontaneität $=$ Weltseele, oder das hochste Prinzip der Naturphilosophie por Eschenmayer e o já citado Über den wahren Begriff der Naturphilosophie de Schelling. O primeiro acreditava ser a espontaneidade o elemento originário da pulsão na natureza, cuja fonte era o espírito. A aparente atividade de autodeterminação da natureza, para Eschenmayer seria uma projeção da nossa atividade humana autodeterminante isto é, a espontaneidade. Através deste ato de espontaneidade do sujeito, a natureza é levada à sua complexificação, porém derivada de um ato ainda mais complexo, a saber, do sujeito em sua livre ação, de modo que não havia nenhum outro princípio do devir. Esta concepção, naquele momento, estava na contramão de Schelling, para quem a consciência, através da intuição intelectual, deveria voltar à imanência com a natureza a fim de que se despontenciasse de sua unilateralidade transcendental e entrasse na estrutura racional da natureza. ${ }^{10}$

A intromissão deste conceito anos depois daquela controvérsia, no possível ocaso da filosofia da identidade, não foi por acaso. Parece haver um paralelo entre as críticas anteriores de Eschenmayer e as razões que o levaram a apostar na não-filosofia. $O$ fato é que o ato livre de espontaneidade requerido anteriormente parece ser exatamente o que faltava à filosofia da identidade para conferir vida e movimento ao sistema. Contudo, diferente do que pretendia Eschenmayer, naquele momento influenciado por Fichte, a introdução agora do elemen-

$10 \quad$ Sobre a disputa entre Schelling e Eschenmayer em 1801, Cf. Berger e Whistler, 2020, pp. 1-14. 
to da queda traz a possibilidade de um Absoluto que também pode ser livre do seu próprio ser, mas não um ser Absoluto como origem ou "objetivo final da filosofalidade" (EHRHARDT, 2008, p. 66), cujo alcance era apenas uma absolutidade produzida pela mera negação de todos os determinantes, como indicava a mais recente crítica de Eschenmayer.

Diante disso, na realidade, a aceitação, ou não, daquele argumento do salto, ou queda, significar de fato um ato de liberdade, jamais concebido anteriormente pelo programa especulativo da filosofia da identidade, cuja ação representava a resposta de Schelling lançada então pelo desafio de Eschenmayer - para quem a especulação possuía lá seus limites a respeito dos assuntos insondáveis - demarca a questão: Schelling permanece fiel ou não ao domínio puramente racional no tocante à apreensão das verdades eternas? De uma perspectiva mais ampla, certamente é possível dizer que ele alarga sua dúvida a respeito da possibilidade de o Absoluto ser apreendido filosoficamente pela metafísica racional. A respeito disso, Dreher é cirúrgico:

A realidade do desprendimento, porém, é ela própria algo de inassimilável pela razão; o conceito concreto de liberdade só pode ser aproximado, mas não explicado ou justificado pela razão. [...] Mas em Schelling torna-se imperativo equilibrar este abismo da liberdade, que beirava já a dimensão do irracional, com uma visão metafísica de fundo que a compatibilizasse com o caráter de fundamento do Absoluto (DREHER, 2004, p. 71).

Aquela convicção fundamental, defendida aqui, de que o incondicionado independe da consciência é assim complementada pela certeza de que em nada ajudaria mais apostar todas as fichas num método do saber, seja ele reflexivo, do entendimento, especulativo, da razão, e tutti quanti, para a compreensão da deidade, pois, com a possibilidade da queda, "a liberdade é a primeira testemunha do Absoluto" (EHRHARDT, 2008, pp. 66-67). Este seria então o ponto de inflexão que Alfred Denker (2000, p. 400) afirma encontrar em Philosophie und Religion. A referência é em relação ao novo ponto de partida que Schelling assume em detrimento do programa de "metafísica absoluta" desenvolvido com Hegel em 1801. ${ }^{11}$

$11 \quad$ A respeito do programa de metafísica absoluta desenvolvido anteriormente, Cf. Düsing, 1993. 
Isso quer dizer que a dimensão da finitude já não corresponde mais inteiramente àquela incapacidade de a consciência conceber a identidade de Deus diante daqueles dois polos tematizados anteriormente, de natureza e espírito. Schelling quer agora a focalização naquilo que é o caso e isso aponta para além de uma oposição cognitiva: "na medida em que Deus é, agora, uma vida e uma força, inteiramente ativo, moral e espontâneo, seu oposto precisa se configurar dramaticamente, como algo igualmente vivo" (COELHO, 2018, p. 25, grifo nosso). Essa vida corresponde àquele abismo de todo ser revelado na finitude pela queda.

Este fundamento ou abismo originário é a indiferença de sujeito-objeto já presente no sistema da identidade, só que agora pensada no registro do movimento, pensada como princípio e fonte criativa que pode produzir um mundo finito "real" no nosso sentido mais corriqueiro da palavra (DREHER, 2017, pp. 70-71).

Por um lado, com esse abismo fica explicitado que a verdadeira relação metafísica do Absoluto não seria aquela da identidade entre natureza e espírito, mas sim aquela vivificada, entre necessidade, ou dependência, e liberdade. Schelling não pensa o Absoluto como o reino da identidade absoluta amorfa, mas como Deus vivo, ao qual toda finitude repousa, não apenas subsistindo, mas como seres vivos e ligados a ele por meio da relação entre fundamento e existência. Por outro, mesmo no âmbito das Investigações Filosóficas sobre a Essência da Liberdade Humana (1809), esse deslocamento deve ser visto necessariamente como um passo adiante em relação àquela relação anterior e não como uma supressão dela, pois: "aquela raiz da oposição foi agora arrancada e a posse de um ponto de vista mais rigoroso pode tranquilamente ser confiada ao progresso geral em direcção a um melhor conhecimento" (SCHELLING, 1993, p. 31). Nessa perspectiva, Tilliette, por exemplo, mantém a convicção de que "Philosophie und Religion não perturba a fachada da identidade" (TILLIETE, 1970, p. 479). Dale Snow, tal qual, no que diz respeito às Investigações, concebe Schelling não desvalorizando a razão,

[...] mas prestando o devido respeito ao reconhecer sua história, seu contexto. Esse contexto, falando de maneira geral, é o seu crescimento a partir da irracionalidade do ser primordial; a natureza é 
transfigurada na inteligência, mas não há cruzamento místico inteiramente para outra ordem de ser, como acontece com Descartes. Schelling insiste que tanto a natureza quanto a inteligência devem estar presentes naqueles que de fato conhecem um ou outro. Assim, a razão e seus limites não são mais o foco central, pois Schelling está preocupado neste tratado com uma questão mais vital: qual é a essência da liberdade humana? (SNOW, 2000, p. 317).

Doravante, isso passava por reconhecer que

[...] por mais alto que coloquem a razão, não acreditamos que alguém, por exemplo, possa ser virtuoso, ou herói, ou em geral um grande homem, devido à pura razão; e nem sequer que, segundo a expressão corrente, o gênero humano se perpetue através dela" (SCHELLING, 1993, p. 129).

O que estava em jogo a partir de então era a dissolução de um certo tipo de subjetividade purista derivada da herança kantiana e que levou Schelling a apostar naquela metafísica absoluta com base na razão de outrora. A nova perspectiva colocava que a razão ainda é parte do objetivo pleno de reintegrar a diferença à identidade, "mas ela é também mais viva e mais real quando reconstitui diferenças objetivas do que quando a identidade já está abstratamente dada" (COELHO, 2018, p. 23).

De modo mais geral, na contramão de Jacobi, Schelling quer persuadir que não há antagonismo entre a ideia de liberdade e a ideia de sistema, cujo objetivo fundamental seria "conciliar panteísmo ("sistema") e liberdade através de um conceito de identidade que preserve continuidade e diferença, dependência e autonomia dos relata, p. ex. Deus e homem" (DREHER, 2017, p. 53). Isso torna-se possível através do fato de que o Absoluto só poderia se reconhecer objetivado em outro Absoluto, contudo, onde as potencialidades de um e outro não estivessem reclusas ao âmbito cognitivo. Elas deveriam carecer das mesmas forças volitivas, de forma que gerassem uma relação mútua de dependência e autonomia, e, então, uma identidade complexificada que "torna solúvel em Deus a unidade indissolúvel entre subjetivo e objetivo" (SNOW, 2000, pp. 323-324).

Essa perspectiva, chamada por Coelho de "monismo complexificado", poderia facilmente ser chamada de monismo espiritualizado, pois, como ele próprio afirma, "Schelling, como 
os demais idealistas e românticos, preferia sempre falar de uma anima mundi, não de um Todo imóvel" (COELHO, 2018, p. 15). Essa característica espiritualista da filosofia de Schelling, que foi desenvolvida como herança da visão mística do mundo suábio, tal como a valorização do pensamento de figuras como Giordano Bruno e Böhme (este último principalmente através da recuperação feita por Baader), aparece inclusa como um terceiro na sucessão de elementos presentes nesse monismo espiritualizado. ${ }^{12}$ Os dois primeiros elementos obviamente dizem respeito à noção de liberdade humana herdada de Kant e à inclusão da visão panteísta de Espinosa. Esta espiritualização aparece como um terceiro tanto do ponto de vista histórico, isto é, na sucessão do desenvolvimento de sua filosofia, quanto na posição específica que ocupa filosoficamente em relação aos dois anteriores. Na verdade, essa realidade tematizada acerca daquilo que é o caso do mundo pressupunha a necessidade de fundamentação da unidade de dois elementos, ou seja, tanto de um teísmo quanto de uma visão panteísta. Liberdade e dependência aqui são conceitos sinônimos destas mesmas figuras, mas pensadas a partir de um ponto onde a identidade entre espírito e natureza já estivesse pressuposta: “aquele é o projeto total de Schelling desde que apresentou separadamente as 'partes' do seu primeiro sistema como filosofia da natureza e como idealismo transcendental" (DREHER, 2017, p. 53).

Deste modo, o critério que valida os diversos intentos de Schelling considera que "é necessária a conciliação entre uma transcendência imanente e uma recíproca constituição purista da subjetividade em si mesma" (COELHO, 2018, p. 23). Deste modo, o critério recai na investigação dos modos de relação dessa subjetividade mediante àquela realidade espiritualizada, ou seja, a maneira como Schelling acreditava ser possível conciliar "o real conceito de liberdade enquanto uma efetiva 'faculdade do Bem e do Mal', sem desistir da idéia de uma 'imanência das coisas em Deus"' (DREHER, 2004, p. 67). Diante disso, a

$\overline{12}$ Segundo Coelho, (2018, p. 17), "a julgar pela interpretação de Baader sobre o pensamento de Böhme, Deus é o centro onipresente de todas as coisas (panteísmo) e igualmente um outro que precede e se coloca acima de todas as coisas (teísmo) [...] Nem panteísmo nem dualismo. Deus é o outro que está em tudo: panenteísmo". 
evidência a ser tratada agora seria a do próprio agir em meio a esta perspectiva da queda da identidade enquanto indiferença, e isto pressupõe tematizar a oposição entre necessidade e liberdade como a "autêntica oposição" (SCHELLING, 1993, p. 32).

\section{Referências}

BECKENKAMP, Joãosinho. A penetração do panteísmo na filosofia alemã. O que nos faz pensar, v. 14, n. 19, pp. 7-27, 2004.

BERGER, Benjamin; WHISTLER Daniel. The Schelling-Eschenmayer Controversy, 1801. Edinburgh University Press, 2020.

COELHO, Humberto S. O monismo complexificado de Schelling. Cadernos De Filosofia Alemã: Crítica e Modernidade, v. 23, n. 1, pp. 13-26, 2018.

DENKER, Alfred. Three Men Standing over a Dead Dog: The Absolute as Fundamental Problem of German Idealism. In: ASMUTH, Christian.; DENKER, Alfred.; VATER, Michael. Schelling. Zwischen Fichte und Hegel. Bochumer Studien zur Philosophie 32. Amsterdam: Grüner, 2000.

DREHER, Luís H. Dependência e liberdade: Schleiermacher, Schelling e os modos da relação com o Absoluto. Numem, v. 7, n. 2, pp. 59-77, 2004.

DREHER, Luís H. Liberdade e vontade: Schelling leitor de Lutero. Revista de Filosofia Moderna e Contemporânea, v.5, n. 2, pp. 43-76, 2017.

DÜSING, Klaus. Die Entstehung des spekulativen Idealismus.

Schellings und Hegels Wandlungen zwischen 1800 und 1801. In: JAESCHKE, W. (Ed.). Transzendentalphilosophie und Spekulation:

Der Streit um die Gestalt einer ersten Philosophie (1799-1807). Meiner Verlag, 1993.

EHRHARDT, Walter E. Einleitende Bemerkungen über Philosophie und Religion im Kontext von Schellings Werk. In: SCHELLING, F.W.J. Philosophie und Religion. Hrsg. Alfred Denker e Holger Zaborowski. München: Freiburg im Breisgau, 2008.

ESCHENMAYER, C. A. Die Philosophie in ihrer Uebergang zur Nichtphilosophie. Erlangen: in der Waltherschen Kunst und Buchhandlung, 1803.

FICHTE. J. G. A Doutrina da Ciência de 1794. In: Os Pensadores, $2^{\mathrm{a}}$ ed. Tradução Rubens Rodrigues Torres Filho. São Paulo: Abril Cultural, 1984.

FLORIG, Oliver. Die ideelle Reihe der Philosophie: Philosophie und Religion als Versuch, menschliche Freiheit im Identitätssystem zu denken. In: SCHELLING, F.W.J. Philosophie und Religion. Hrsg. Al- 
fred Denker e Holger Zaborowski. München: Freiburg im Breisgau, 2008.

FRANK, Manfred. Reduplikative Identität. Der Schlüssel zu Schellings reifer Philosophie. Stuttgart: Friedrich Frommann Verlag Gunther, 2018.

GARDNER, Sebastian. Fichte and Schelling: The Limitations of the Wissenschaftslehre? In: JAMES, David; ZOLLLER, Günter (Ed.). The Cambridge Companion to Fichte. Cambridge: Cambridge University Press, 2016.

HEGEL, G. W. F. Diferença entre os sistemas filosóficos de Fichte e de Schelling. Tradução Carlos Morujão. Lisboa: Casa da Moeda, 2003.

HEGEL, G. W. F. Briefe von und an Hegel: Bande 1. 1785-1812. Hamburg: Felix Meiner, 1952.

HENNIGFELD, Jochem. Identität und Freiheit in Schellings Systementwürfen 1801-1809. In BAIER, Karl; ZERBST, Arne. Gott, Natur, Kunst und Geschichte: Schelling zwischen Identitätsphilosophie und Freiheitsschrift. Vandenhoeck \& Ruprecht, 2011.

HENNIGFELD, Jochem. Friedrich Wilhelm Joseph Schellings Philosophische Untersuchungen über das Wesen der Menschlichen Freiheit und die Damit Zusammenhängenden Gegenstände. Wissenschaftliche Buchgesellschaft, 2001.

IBER, Christian. O perfil filosófico de Schelling. Porto Alegre: Editora Fi, 2015.

JACOBI, Friedrich H. Jacobi an Fichte (1799). In: JACOBI, Friedrich H. Schriften zum transzendentalen Idealismus. Hamburg: Felix Meiner Verlag. 2004.

MARQUET, Jean-François. Liberté et existence: Étude sur la formation de la philosophie de Schelling. Paris: Gallimard, 1973.

SCHELLING, F. W. J. Cartas filosóficas sobre o dogmatismo e o criticismo. In: Os Pensadores, $3^{\mathrm{a}}$ ed. Tradução Rubens Rodrigues Torres Filho. São Paulo: Abril Cultural, 1989.

SCHELLING, F. W. J. Presentation of my system of philosophy. Tradução Michael G. Vater. Philosophical Forum, v. 32. No. 4, pp. 339-371, 2001.

SCHELLING, F. W. J. Filosofia da Arte. Tradução Márcio Suzuki. São Paulo: EDUSP, 2010.

SCHELLING, F. W. J. Investigações filosóficas sobre a essência da liberdade humana e os assuntos com ela relacionados. Tradução e Prefácio Carlos Morujão. Lisboa: Edições 70, 1993.

SCHELLING, F. W. J. Sobre el verdadero concepto de la filosofía de la naturaleza. In: SCHELLING, F. W. J. Escritos sobre filosofía de la naturaleza. Tradução Arturo Leyte. Madrid: Alianza Editorial, 1996. 
SCHELLING, F. W. J. Brief an C.A. Eschenmayer, 30/07/1805. In: SCHELLING, F. W. J. Briefe und Dokumente. Bonn: Bouvier, 1962.

SCHELLING, F. W. J. Philosophie und Religion. Tübingen: J. G. Cotta'sche Buchhandlung, 1804.

SCHELLING, F. W. J. Sistema del Idealismo transcendental. Tradução e notas Jacinto Rivera de Rosales y Virginia López Domínguez. Rubí. Barcelona: Anthropos Editorial, 2005.

SCHELLING, F. W. J. Aforismos para introdução à filosofia da natureza e aforismos sobre filosofia da natureza. Tradução Márcia Gonçalves. Rio de Janeiro: Ed. PUC-Rio, 2010.

SNOW, Dale E. The Evolution of Schelling's Concept of Freedom. In: ASMUTH, Christian.; DENKER, Alfred.; VATER, Michael. Schelling. Zwischen Fichte und Hegel. Bochumer Studien zur Philosophie 32. Amsterdam: Grüner, 2000.

TILLIETTE, Xavier. Schelling: Une philosophie en devenir. vol. 1. Paris: Vrin, 1970.

TILLIETTE, Xavier. Hegel et Schelling à Iéna. Revue de métaphysique et de morale, v. 73, n. 2, pp. 149-166, 1968.

VATER, Michael. Reconfiguring Identity in Schelling's Würzburg System. Schelling-Studien 2, pp. 127-144, 2014. 